projectors. The videotapes contain interviews by general medical practitioners. The package was available from the College at a price of $\$ 30$. So far we have distributed 500 and no longer have any in stock. Two further video training packages are currently in production, the first is aimed at teaching GPs basic cognitive techniques and the second will be targeting counsellors working in primary care.

Although I am disappointed that Dr Snaith has not appreciated the full extent of our educational programme so far, I am pleased to have the opportunity to correct a false impression that may have been shared by other readers.

PAYKEL. E.S. \& PrIEST, R.G. (1992) Recognition and management of depression in general practice: consensus statement. British Medical Journal, 305, 1198-1202.

ROBIN PRIEST, Chairman, Defeat Depression Campaign Management Committee, 17 Belgrave Square, London SW 1X 8PG

\section{Screening for mental illness in the elderly}

Sir: Noble's study (Psychiatric Bulletin, February 1994, 18, 111-112) on the content of over-75s health checks by Norfolk GPs is similar to one we undertook in Milton Keynes. We surveyed all 29 local general practitioners (GP) principals on their methods of screening the over-75s and received replies from $27(93 \%)$. At least $16(59 \%)$ of practices used questionnaires for screening. None appeared to use a validated depression rating scale, but 9 (33\%) did attempt to identify depression - a typical method being a scale such as 'no problems' (score $=0$ ), 'discontented' (score $=2)$, 'very unhappy' (score=4). Cognitive function was generally better examined with 14 (52\%) of practices specifically testing it, e.g. a 10-item test covering memory, orientation and concentration. Those routinely involved in screening included: GPs $(56 \%)$, practice nurses (67\%), district nurses $(48 \%)$, health visitors (11\%) and 'others' (4\%). General comments were also obtained - $6(22 \%)$ expressed dissatisfaction with routine screening describing it as 'unnecessary', 'wasteful of time and energy' and 'intrusive'. Only 1 (4\%) was positive - describing screening as 'worthwhile' - the remaining 20 (74\%) expressed no particular opinion on its value.

We agree with Noble that opportunities for early diagnosis of depression are being missed. Nevertheless, our study suggests that a substantial minority (33\%) of GPs in Milton Keynes attempt to identify depression - albeit using inadequate techniques. This could be improved with better training, more appropriate methods and closer links with psychogeriatric services. One potentially useful screening instrument for depression in general practice is BASDEC (an adaptation of the depression scale for the Brief Assessment Schedule as a set of cards). This has been shown to be quick, valid and acceptable in screening elderly medical in-patients (Adshead et al, 1992).

Community studies of depression and dementia in the over-65s have shown high prevalence rates of $11.3 \%$ and $5.2 \%$ respectively (Copeland et al, 1987). Screening seems a logical way to identify these common illnesses but at least six (22\%) of our GPs are not convinced that routine screening is worthwhile. At present there is a lack of strong evidence to change their minds. We echo Noble's call for greater co-operation and research between psychiatrists and GPs to resolve this question.

ADshend. F., Day CODY, D. \& PITT. B. (1992) BASDEC: a novel screening instrument for depression in elderly medical inpatients. British Medical Journal, 305, 397.

COPELAND, J.R.M., DEWEY, M.E. \& WoOD. N. (1987) Range of mental illness among the elderly in the community: prevalence in Liverpool using the GMS-AGECAT Package. Brttish Journal of Psychiatry. 160, 815-823.

J.D.D. LAIDLAW and E. ZAPATA, Department of Psychiatry for the Elderly, Campbell Centre, Muton Keynes MK6 5LE

\section{Evaluation of counselling services}

Sir: Having recently completed an evaluation of the first three years of a counselling service for carers of people attending the Bristol Memory Disorders Clinic, we would like to expand on the ideas put forward by Michael King (Psychiatric Bulletin, February 1994, 18, 65-67). Our evaluation has shown that there are many unresolved difficulties associated with this exercise.

First, one has to decide on an end point. At what stage can you say that counselling has been successful? We originally thought that a mark of success in our setting would be to keep people out of institutional care. But many counselling sessions has involved helping carers let go, while maintaining their own integrity and that of their relationship with the person with dementia.

There are difficulties associated with how to measure emotions in an objective way, and how to measure change in these emotions. When working with a progressive condition like dementia, it is possible that counselling is perceived as beneficial but there is little or no change on a quantitative scale. Doctors work from a scientific background and are used to looking for hard data, but we have found that it is very difficult to measure emotion and stress solely in these terms. 